\title{
The Life History and Population Growth Parameters of Leaf Eating Caterpillar Cricula trifenestrata Helfer (Lepidoptera: Saturniidae) Infesting Manochilus bombycina King
}

\author{
S.K. Gharde* and N. Chaudhuri \\ Department of Agricultural Entomology, Uttar Banga Krishi Viswavidyalaya, Pundibari, \\ Cooch Behar-736165, West Bengal, India \\ Department of Plant Protection, Lovely Professional University, Phagwara, Jalandhar- \\ 144411 Punjab, India \\ Discipline of Agricultural Entomology, Regional Research Station, Terai Zone, Uttar Banga \\ Krishi Viswavidyalaya, Pundibari, Cooch Behar-736165, West Bengal, India \\ *Corresponding author
}

\begin{tabular}{|l|}
\hline Ke y w o r d s \\
$\begin{array}{l}\text { Cricula trifenestrata, } \\
\text { Development, } \\
\text { Survivorship, Life } \\
\text { table }\end{array}$ \\
\hline Article Info \\
\hline $\begin{array}{l}\text { Accepted: } \\
\text { 07 January 2018 } \\
\text { Available Online: } \\
\text { 10 February 2018 }\end{array}$ \\
\hline
\end{tabular}

A B S T R A C T

The goal of this experiment was to study the life history and population growth parameters of Cricula trifenestrata Helfer (Lepidoptera: Saturniidae) reared on Machilus bombycina King, the food plant of muga silkworm (Antheraea assama Westwood). Biological and life table parameters differed significantly in different generations. The longest and shortest larval period of $43.68 \pm 1.34$ and $38.67 \pm 1.13$ days were recorded in January-March and May-October generations respectively. The development time of total pre adult was shortest in March-May (77.12 \pm 1.73 and 78.42 \pm 1.60 days for male and female) generation. The egg to adult survivorship and fecundity were highest in October-January generation $(49.00 \pm 1.45 \%$ and $122.35 \pm 3.02)$. The sex ratio was male-biased. The highest intrinsic rate of increase $(r \mathrm{~m})$, finite rate of increase $(\lambda)$ and the shortest mean generation $(G T)$ and doubling time $(T d)$ were recorded during January-March. The lowest intrinsic rate of increase $(r \mathrm{~m})$, finite rate of increase $(\lambda)$ and the longest mean generation time $(G T)$ and doubling time $(T \mathrm{~d})$ were recorded during May-October. The highest and lowest net reproductive rate $(R \mathrm{o})$ and potential fecundity occurred in female of October-January and March-May generation respectively. The results revealed that May-October was the most unsuitable month for population growth of $C$. trifenestrata. So, control measure if be taken for the pest during May to October, then the percent of damage caused by the caterpillar can be minimized, that might improve the performance of Antheraea assama during commercial rearing seasons in terai region of West Bengal.

\section{Introduction}

Machilus bombycina King (Lauraceae: Laurales) is one of the primary host plants of the muga silkworm Antheraea assama Ww. (Saturniidae: Lepidoptera). The plant is evergreen with spreading branches and is very common to Assam, Meghalaya and northern 
tract of West Bengal in India (Singh et al., 2000). The northern tract of West Bengal, particularly Cooch Behar, Alipurduar and Jalpaiguri districts, has been explored as new area of muga culture since being contiguous to lower Assam, agro-ecologically, socio-ethnoeconomically. The successful rearing of this world famous silkworm depends on availability of quality leaves of its food plants apart from other management and climatic factors. The leaf eating caterpillar, Cricula trifenestrata Helfer, a saturniid wild silkmoth is the most serious insect-pest of Machilus bombycina King. The caterpillar in its last stage eats $69-72 \%$ of the total intake and the last three stages are capable of eating more than $95-97 \%$ of the total intake (Gharde, 2016). In a severe case, the caterpillars devour the entire leaf blade except the midrib giving a broom like appearance in Machilus bombycina King plant and thus hinder successful rearing of muga silkworm during commercial seasons (Ahmed et al., 2012).

As muga silkworm is also a Saturniid insect, so care should be taken in regards to safety of the silkworm while adopting the control measures against $C$. trifenestrata. It is widely distributed in the Indian Sub-continent, thriving on different host plants of economic importance like cashew Anacardium occidentale (Mandal, 2000; Rajesh and Zachariah, 2011 and Pal and Medda, 2006), Cinnamomum zeylanicum (Ahmad and Ahmad, 1991), Cardamom (Yadav and Kumar, 2003), Som (Machilus bombycina) (Tikader, 2011; Ahmed et al., 2012), litchi (Litchi chinensis Sonn.), and tea plantations (Arora and Gupta, 1979; Das et al., 1999). The in depth study of the population growth pattern is essential to develop management strategies against polyphagous pest. Since there is no information on life history and the age-stage life table parameters of this pest, the present study was conducted to study the potential of population growth of $C$. trifenestra in terai region of West Bengal,
India. The information provided in this investigation should be essential in understanding the dynamics of $C$. trifenestrata and should contribute to an integrated management action plan that allows for targeted suppression of the pest.

\section{Materials and Methods}

The experiment was conducted at the laboratory of the department of Agricultural Entomology and Instructional Farm, Uttar Banga Krishi Viswavidyalaya, Pundibari, Cooch Behar during 2013 to 2015.

\section{Specimen collection and rearing of insects}

Pupae of Cricula trifenestrata were collected in nature and brought to the laboratory, Department of Agricultural Entomology. They were kept in rearing cages $2 \mathrm{ft}$ (height) $\mathrm{x} 1.5 \mathrm{ft}$ (width) $\mathrm{x} 2 \mathrm{ft}$ (depth) for adult emergence. Upon emergence of the adults, the male and female moths were identified using spots on wings and size, and finally they were placed couple wise in the separate cages containing twigs of Machilus bombycina to carry out their normal life. Once laid, batches of eggs were transferred to petridish carefully for hatching. Twigs of $M$. bombycina were provided as food, with their cut ends immersed in water-filled small plastic tubes so that neonates could obtain ready food immediately after hatching. Twigs of leaves were arranged in such a way that enough space in between leaves was present for free movement of the tiny caterpillars. Mass cultures on different hosts were maintained under the laboratory conditions.

\section{Host plant materials}

For the experiment, the food plant Machilus bombycina King of the family Lauraceae were collected from the Instructional Farm of Uttar Banga Krishi Viswavidyalaya, located under 
Terai region of West Bengal, India. The plants selected for the study were of fifteen (15) years old. The experimental domain is situated between $26^{\circ} 19^{\prime} 86^{\prime \prime} \mathrm{N}$ latitude and $89^{\circ} 23^{\prime} 53^{\prime \prime} \mathrm{E}$ longitude at an elevation of $43.0 \mathrm{~m}$ above mean sea level.

Assessment of $C$. trifenestrata development, survivorship and sex ratio on the different host plants

Hundred eggs (collected within $12 \mathrm{~h}$ ) were collected and the twig with egg was placed in a water filled conical flask lined with wet cotton to prevent desiccation. This was checked twice daily for egg hatch. The development of the insect from egg stage to adult emergence was observed. The sex of the adults was identified after emergence based on the spots present on the fore wings. The following data were collected for each host plant: (1) developmental duration from egg to adult, (2) percentage of insects reaching adult stage, and (3) sex ratio, measured as proportion of females out of the total number of $C$. trifenestrata $[q /(q+0)]$. The experiment was replicated 5 times.

\section{Reproduction and assessment of demographic parameters}

Thirty randomly selected newly emerged adults @ 2:1 (male: female) were used to determine the reproduction and longevity of C. trifenestrata. The adults were kept in the cages for mating and after mating the females were transferred individually to cages with twig of host plant species in water filled conical flask $(150 \mathrm{ml})$ and observed daily until they died. The total number of eggs produced by each female was recorded daily. Standard life table parameters including female survivorship ( $l \mathrm{x}$; the fraction of females surviving to age $x$ ) and age-specific fecundity $(m x$; mean number of female progeny per female per day) were calculated from daily records of mortality and fecundity of cohorts on each host plant. Each female was considered a replicate.

\section{Statistical analysis}

Adult survivor percentage and sex ratio of $C$. trifenestrata was transformed (angular) before analysis. Data on the developmental time for egg, larva, pupa, total pre-adult, adult longevity, total lifespan, survivorship and sex ratio of $C$. trifenestrata were subjected to oneway analysis of variance (ANOVA) using the PROC GLM in SAS (Ver. 9.2).

Life table for each host plant species was constructed following the method described by Carey (1993) and the intrinsic rate of increase $(r \mathrm{~m})$, net reproductive rate $(R \mathrm{o})$, mean generation time $(G T)$, doubling time $(T d)$ and finite rate of increase $(\lambda)$ ) were estimated using the Jackknife program (Maia et al., 2000). Differences between life table parameters across the different generations completed in a year was estimated by one-way analysis of variance (ANOVA) using GLM procedure (SAS, Ver. 9.2).

\section{Results and Discussion}

\section{Development time}

The results of the development of immature stages are given in Table 1. Regarding the results, significant difference was observed for egg incubation, larval and pupal period of $C$. trifenestrata in different generations $(\mathrm{P}<0.05)$. The longest and shortest values of larval period were $43.68 \pm 1.34$ and $38.67 \pm 1.13$ days in May-October and January-March generation. The longest pupal $(89.10 \pm 3.00$ and $92.78 \pm 3.41$ days for male and female) and development time of total pre-adult (138.26 \pm 3.25 and 142.52 \pm 3.06 days for male and female) were recorded during MayOctober. The pupal period was shortest during 
January-March $(22.40 \pm 1.05$ and $23.50 \pm 1.22$ days for male and female) and the total preadult days were shortest during March-May (77.12 \pm 1.73 and $78.42 \pm 1.60$ days for male and female).

\section{Longevity, fecundity, life span, survivorship and sex ratio}

Adult longevity, fecundity, adult survivor and sex ratio of $C$. trifenestrata adults are given in Table 2. Different rearing months had no significant effect on longevity of adult male. The female longevity and adult survivorship of $C$. trifenestrata was significantly highest in October-January generation (4.13 \pm 0.19 days and $49.00 \pm 1.45 \%$ respectively). The lifespan of $C$. trifenestrata was also varied significantly among different generations and it was longest in May-October (140.95 \pm 3.11 and $145.25 \pm 3.11$ days for male and female) and shortest in March-May (79.85 \pm 2.17 and $82.00 \pm 1.58$ days for male and female). There was a significant difference in the total number of eggs per individual female in different generations $(\mathrm{P}<0.05)$, which was highest in October-January (122.35 $\pm 3.02 /$ female) and lowest in MarchMay (72.00 $\pm 2.08 /$ female). Sex ratio was male biased. It ranged from $0.32 \pm 0.02$ to $0.34 \pm 0.01$ in three generations extended from January to October. In October-January generation the female sex ratio was lowest $(0.29 \pm 0.01)$ (Table. 2).

\section{Age-specific fecundity and survivorship}

The $l x$ is the probability that an egg will survive to age $x$. The age-specific survivorship (lx) of female curves decreased gradually and asymptotically as $C$. trifenestrata aged (Fig. $1)$. The female survivor was highest in October-January generation (14\%). The entire Cricula cohort died on 86 days during MarchMay and 150 days during May-October generations.
The age-specific fecundity $(m x)$ gives the number of offspring produced per day by an individual at age $x$. The curves of age-specific fecundity $(m \mathrm{x})$ for $C$. trifenestrata in different generations peaked soon after the onset of reproduction and varied considerably among the different generations (Fig. 1). The insect laid eggs for three days.

More than $60 \%$ of eggs were laid on $1^{\text {st }}$ day of oviposition. It was on 70-82 day in MarchMay generation, 82-84 day in January-March generation, 144-146 day in May-October generation and 109-111 day in OctoberJanuary generation. The mean number of female progeny $(\mathrm{mx})$ produced in $1^{\text {st }}$ day of oviposition was highest in October-January $(21.60 \% / 9 /$ day) and lowest in March-May (15.14 $/$ / $/$ /day). Age-specific maternity $(l \mathrm{x} m \mathrm{x})$ of $C$. trifenestrata was also highest in October-January and lowest in March-May.

\section{Population growth statistics}

There present a profound effect of different generations on all growth parameters [net reproductive rate $(R \mathrm{o})$, intrinsic rate of increase $(r \mathrm{~m})$, population doubling time $(T \mathrm{~d})$, generation time $(G T)$ and infinite rate of increase $(\lambda)$ ] evaluated (Table 3 ).

The potential fecundity of female was highest in October-January (34.10 $\pm 1.40 /$ female). It was followed by May-October $(27.22 \pm 1.59 /$ female $)$ and January-March (26.63 $\pm 0.96 /$ female) generations. In MarchMay it was the minimum (24.24 $\pm 0.77 / \mathrm{female})$. This suggests higher level of population in the field from October to May. The net reproductive rate $(R 0)$ was found to be significantly different in different generations. The rate was highest $(4.79 \pm 0.61$ o/P/generation) in October-January followed by $3.59 \pm 0.35$ q $/$ / $/$ generation in May-October and lowest in March-May generation (3.07 \pm 0.58 P/ $/$ /generation). 
Table.1 The mean $( \pm \mathrm{SD})$ duration of immature stages (days) of $C$. trifenestrata reared on Machilus bombycina King

\begin{tabular}{|l|c|c|c|c|c|c|}
\hline Generations & $\begin{array}{c}\text { Incubation } \\
\text { (days) }\end{array}$ & \multirow{2}{*}{ Larval (days) } & \multicolumn{2}{|c|}{ Pupal (days) } & \multicolumn{2}{c|}{ Total pre-adult (days) } \\
\cline { 4 - 7 } & & Male & Female & Male & Female \\
\hline January-March & $14.46 \pm 1.02 \mathrm{a}$ & $43.68 \pm 1.34 \mathrm{a}$ & $22.40 \pm 1.05 \mathrm{~d}$ & $23.50 \pm 1.22 \mathrm{c}$ & $80.14 \pm 1.99 \mathrm{c}$ & $81.26 \pm 1.26 \mathrm{c}$ \\
\hline March-May & $10.12 \pm 0.68 \mathrm{~b}$ & $41.85 \pm 1.55 \mathrm{~b}$ & $25.30 \pm 1.14 \mathrm{c}$ & $26.75 \pm 1.06 \mathrm{c}$ & $77.12 \pm 1.73 \mathrm{c}$ & $78.42 \pm 1.60 \mathrm{~d}$ \\
\hline May-October & $10.07 \pm 0.76 \mathrm{~b}$ & $39.67 \pm 1.13 \mathrm{c}$ & $89.10 \pm 3.00 \mathrm{a}$ & $92.78 \pm 3.41 \mathrm{a}$ & $138.26 \pm 3.25 \mathrm{a}$ & $142.52 \pm 3.06 \mathrm{a}$ \\
\hline October-January & $10.06 \pm 0.80 \mathrm{~b}$ & $40.00 \pm 1.00 \mathrm{c}$ & $55.10 \pm 1.89 \mathrm{~b}$ & $59.42 \pm 1.46 \mathrm{~b}$ & $104.85 \pm 2.40 \mathrm{~b}$ & $109.48 \pm 1.50 \mathrm{~b}$ \\
\hline $\boldsymbol{F}$ & 33.46 & 11.36 & 1601.15 & 1368.33 & 1229.11 & 1126.43 \\
\hline $\boldsymbol{P}$ & $<0.0001$ & 0.0004 & $<0.0001$ & $<0.0001$ & $<0.0001$ & $<0.0001$ \\
\hline LSD & 1.17 & 1.70 & 2.40 & 2.70 & 2.49 & 2.74 \\
\hline
\end{tabular}

Means with the different letters in the same column are significantly different $(P=0.05, L S D)$

Table.2 The mean $( \pm \mathrm{SD})$ duration of adult life (days), fecundity, total life span (days), adult emergence \% and sex ratio of $C$. trifenestrata reared on Machilus bombycina King

\begin{tabular}{|c|c|c|c|c|c|c|c|}
\hline \multirow[t]{2}{*}{ Generations } & \multicolumn{2}{|c|}{ Adult (days) } & \multirow{2}{*}{$\begin{array}{c}\text { Total } \\
\text { Fecundity/ } q\end{array}$} & \multicolumn{2}{|c|}{ Total life span (days) } & \multirow{2}{*}{$\begin{array}{c}\text { Adult } \\
\text { survivor \% }\end{array}$} & \multirow{2}{*}{$\begin{array}{c}\text { Sex ratio } \\
\left(+/{ }^{\lambda}\right)\end{array}$} \\
\hline & Male & Female & & Male & Female & & \\
\hline January-March & $3.37 \pm 0.37 \mathrm{a}$ & $3.65 \pm 0.30 \mathrm{bc}$ & $79.02 \pm 2.12 b$ & $83.46 \pm 2.20 \mathrm{~d}$ & $84.68 \pm 1.51 \mathrm{c}$ & $41.26 \pm 1.13 b$ & $0.32 \pm 0.02 \mathrm{a}$ \\
\hline March-May & $3.18 \pm 0.39 a$ & $3.85 \pm 0.31 b$ & $72.00 \pm 2.08 \mathrm{c}$ & $79.85 \pm 2.17 \mathrm{c}$ & $82.00 \pm 1.58 \mathrm{c}$ & $38.49 \pm 1.62 \mathrm{c}$ & $0.34 \pm 0.01 \mathrm{a}$ \\
\hline May-October & $3.01 \pm 0.23 \mathrm{a}$ & $3.38 \pm 0.22 \mathrm{c}$ & $80.12 \pm 1.60 \mathrm{~b}$ & $140.95 \pm 3.11 \mathrm{a}$ & $145.25 \pm 3.11 \mathrm{a}$ & $38.00 \pm 1.66 c$ & $0.34 \pm 0.02 \mathrm{a}$ \\
\hline $\begin{array}{l}\text { October- } \\
\text { January }\end{array}$ & $3.45 \pm 0.30 \mathrm{a}$ & $4.13 \pm 0.19 \mathrm{a}$ & $122.35 \pm 3.02 \mathrm{a}$ & $108.00 \pm 2.55 b$ & $113.02 \pm 2.00 \mathrm{~b}$ & $49.00 \pm 1.45 \mathrm{a}$ & $0.29 \pm 0.01 b$ \\
\hline $\boldsymbol{F}$ & 1.66 & 12.74 & 564.52 & 738.40 & 844.69 & 59.54 & 11.36 \\
\hline$P$ & 0.23 & 0.0005 & $<0.0001$ & $<0.0001$ & $<0.0001$ & $<0.0001$ & 0.0008 \\
\hline$L S D$ & 0.47 & 0.27 & 2.97 & 3.20 & 3.13 & 2.03 & 0.02 \\
\hline
\end{tabular}

Means with the different letters in the same column are significantly different $(P=0.05, L S D)$

Table.3 Life table parameters of Cricula trifenestrata reared on Machilus bombycina King

\begin{tabular}{|l|c|c|c|c|c|c|}
\hline \multirow{2}{*}{ Generations } & \multicolumn{5}{|c|}{ Parameter (Mean \pm SD) } \\
\cline { 2 - 7 } & $\Sigma \mathrm{mx}$ & $\boldsymbol{R o}(\Sigma \mathrm{lxmx})$ & $\boldsymbol{r m}$ & $\boldsymbol{T d}$ & $\boldsymbol{\lambda}$ & $\boldsymbol{G}$ \\
\hline January-March & $26.63 \pm 0.96 \mathrm{~b}$ & $3.48 \pm 0.51 \mathrm{bc}$ & $0.015 \pm 0.0003 \mathrm{a}$ & $45.93 \pm 1.38 \mathrm{c}$ & $1.015 \pm 0.0003 \mathrm{a}$ & $82.56 \pm 2.12 \mathrm{c}$ \\
\hline March-May & $24.24 \pm 0.77 \mathrm{c}$ & $3.07 \pm 0.58 \mathrm{c}$ & $0.014 \pm 0.0003 \mathrm{~b}$ & $49.44 \pm 1.65 \mathrm{~b}$ & $1.014 \pm 0.0004 \mathrm{~b}$ & $79.97 \pm 2.54 \mathrm{c}$ \\
\hline May-October & $27.22 \pm 1.59 \mathrm{~b}$ & $3.59 \pm 0.35 \mathrm{~b}$ & $0.009 \pm 0.0004 \mathrm{~b}$ & $78.06 \pm 2.14 \mathrm{a}$ & $1.009 \pm 0.0004 \mathrm{c}$ & $144.08 \pm 2.20 \mathrm{a}$ \\
\hline October-January & $34.10 \pm 1.40 \mathrm{a}$ & $4.79 \pm 0.61 \mathrm{a}$ & $0.014 \pm 0.0004 \mathrm{c}$ & $48.47 \pm 1.14 \mathrm{~b}$ & $1.014 \pm 0.0004 \mathrm{~b}$ & $109.47 \pm 1.88 \mathrm{~b}$ \\
\hline $\boldsymbol{F}$ & 269.73 & 29.88 & 268.20 & 386.21 & 76.99 & 1198.46 \\
\hline $\boldsymbol{P}$ & $<0.0001$ & $<0.0001$ & $<0.0001$ & $<0.0001$ & $<0.0001$ & $<0.0001$ \\
\hline $\boldsymbol{L S D}$ & 0.80 & 0.42 & 0.0004 & 2.37 & 0.001 & 2.66 \\
\hline
\end{tabular}

Means with the different letters in the same column are significantly different $(P=0.05, L S D)$

$\sum m x=$ potential fecundity (female progeny /female /day),

$R \mathrm{o}=$ net reproductive rate (female offspring/female/generation),

$r \mathrm{~m}=$ intrinsic rate of increase (female eggs/female/day),

$T \mathrm{~d}=$ doubling time (days) and

$\lambda=$ finite rate of increase for population (female offspring/female/day),

$G T=$ mean generation time (days). 
Fig.1 Age-specific fecundity ( $m \mathrm{x})$, age-stage specific maternity (lx $m \mathrm{x})$, and age-specific survivorship (lx) of Cricula trifenestrata reared on Machilus bombycina King



The intrinsic rate of increase $(\mathrm{rm})$ was higher $(0.015 \pm 0.0003$ female eggs/female/day) in January-March generation and the population was expected to double in only 45.93 days. The lowest $r \mathrm{~m}$ was recorded in May-October $(0.009 \pm 0.0004$ female eggs/female/day) with a doubling time of $78.06 \pm 2.14$ days. The finite rate of increase $(\lambda)$ also showed significant differences and was higher (1.015 \pm 0.0003 female offspring/female/day) in January-March generation. It was lowest in May-October generation (Table 2). The lowest generation time of $79.97 \pm 2.54$ days was recorded in March-May generation and the highest duration (144.08 \pm 2.20 days) occurred in May-October generation.

Results of this study showed that the biological and life table parameters of $C$. trifenestrata measured varied significantly across the generations. Previous studies have suggested that $C$. trifenestrata completed four generations in a year (Biswas et al., 2013 and Ghosh et al., 2015). Our results concur with this finding. The duration of development is potentially an important component of fitness, as it will determine how long different developmental stages of the insect will be exposed to predators and parasites. For example, the effectiveness of several natural enemies depends on host growth rates: parasitism increases when host growth is slowed (Benrey and Denno, 1997; Devine et al., 2000). On the other hand, a reduction in developmental duration on an optimal host could represent an advantage to the insect by reducing its vulnerability to parasitism and predation. The development and survival were high in generation completed during October-January. It is probable that some constituent compounds or physiological barriers inherent in this host plant species significantly increases feeding and consequently led to an increment in 
development and survival of $C$. trifenestrata. The May-October generation especially warrants careful monitoring for population buildup of this polyphagous insect. The developmental time and survival of cohorts of C. trifenestrata was lower in March-May generation. $C$. trifenestrata progeny were male biased. Ghorai and Chaudhuri (2012) also reported male biased progeny of another saturniid Antheraea assama Ww.

The life table parameters provide, for the first time, the comprehensive information on the survival, development and reproductive capacity of $C$. trifenestrata infesting Machilus bombycina.

The intrinsic rate of natural increase $(r \mathrm{~m})$ is the most important parameter for describing the growth potential of a population under given climatic and food conditions, as it reflects the overall effect of development, reproduction and survival (Southwood and Handerson 2000). The intrinsic rate of natural increase $(r \mathrm{rm})$ was higher in January-March and October-January generations, suggest higher damage potential of the pest in these months. So the pest could have a higher potential of threatening to $M$. bombycina during commercial rearing season of Antheraea assama.

Overall, the results of this investigation provide strong indication that the population growth parameters, and the timing and extent of damage of $C$. trifenestrata on $M$. bombycina may result in rapid development and greater numbers of the insect surviving to adulthood, and hence more damage on these host plants during October to March; and this observation has significant implications for management of the pest during that period. The lower rate of $R_{0}$ in March-May generation suggests declined rate of population build-up after May. The higher rate of $R_{0}$ in both the generations extends from May to January indicates higher level of population build-up from October, the commercial season for Antheraea assama rearing (Ghosal et al., 2007).

The longer doubling time and lower R0 suggested decline in population after June. So, control measure if be taken for the pest during May to October, then the percent of damage caused by the caterpillar can be minimized, that might improve the performance of Antheraea assama during commercial rearing seasons in terai region of West Bengal.

The life table parameters also provide important new information on the biotic potential of the pest on its host plants that should be useful in developing simulation models that include other factors for field use and management of $C$. trifenestrata. The information provided in this investigation should be essential in understanding the dynamics of $C$. trifenestrata and should contribute to an integrated management action plan that allows for targeted suppression of the pest.

\section{References}

Ahmad, M. and M. Ahmad. 1991. A new host plant record for the mango defoliator, $C$. trifenestrata, from Mymensingh, Bangladesh. Bangladesh J. Entomolo. 1: 89.

Ahmed, S.A., L.C. Dutta and M. C. Sarmah. 2012. Bio-Efficacy of some Insecticides against Leaf Eating Caterpillar, Cricula trifenestrata Helfer (Lepidoptera: Saturniidae) Infesting Som, Persea bombycina Kost. Plant. Aca. J. Entomol. 5: 94-98.

Arora, G.S. and I. J. Gupta. 1979. Taxonomic studies of the some of the Indian vanya silk moths (Lepidoptera: Saturniidae: Saturniinae). Memoirs Zool. Surv. India. 16:1-63.

Benrey, B., and R. F. Denno. 1997. The slow 
growth high mortality hypothesis: a test using the cabbage butterfly. Ecology 78: 987-999.

Biswas, S., T. K. Hath and N. Ray. 2013. Effect of different host plants on nutritional indices of wild silk moth, Cricula trifenestrata. $J$. Ent.Res. 37: 223-227.

Carey, J. R. 1993. Applied demography for biologists with special emphasis on insects. Oxford University Press, New York.

Das, D. K., S.K. Dutta and D.P. Khanikor. 1999. Incidence of insect pests on som in Jorhat and Goalpara districts of Assam. Department of Entomology, Assam Agricultural University, Jorhat 785013, Assam, India. J. Agric Sci. Soc. North East India. 12: 75- 78 .

Devine, G. J., D. J. Wright and I. Denholm. 2000. A parasitic wasp (Eretmocerus mundus Mercet) can exploit chemically induced delays in the development rates of its whitefly host (Bemisia tabaci Genn.). Biol. Control 19: 64-75.

Ghorai, R. and Chaudhuri, N. 2012. Studies on life-fecundity table of Antheraea assama Ww. On Machilusbombycina in terai climatic condition of West Bengal. Research Journal of Agricultural Sciences. 2(4): 233-235.

Ghosal, M., Chaudhuri, N. and Senapati, S.K. 2007. Seasonal variation in rearing performance of muga silkworm (Antheraea assama Ww.). Journal of Plant Protection Environment. 4(2): 41-46.

Ghosh, J., Chaudhuri, N. and Bera, C. 2015. BioEcological analysis to identify the critical stage of development of mango defoliator Cricula trifenestrata (Lepidoptera: Saturniidae). International Journal of Recent Scientific Research. 6(10): 72597262 .
Maia, A. H. N., A. J. B. Luiz and C. Camp anhola. 2000. Statistical inference on associated fertility life table parameters using Jacknife technique: computational aspects. J. Econ. Entomol. 93: 511-518.

Mandal, R.C. 2000. Pests of cashew. In: Cashew production and processing technology. Agrobios, Jodhpur, pp 123.

Nair, M.R.G.K., 1975. In: Insects and mites of crops. Indian Council of Agricultural Research, New Delhi, pp 193.

Pal, S.and P.S. Medda.2006. Occurrence of wild silk moth, Cricula trifenestrata Helfer on cashew (Anacardium occidentale L.) under Terai conditions of West Bengal. Orissa J. Hort. 34:117.

Rajesh, G. and G. Zacharia. 2011. Silk from cashew pest can boost income, In: abstract of Frist International Symposium on Cashew nut-2011, Madurai, December 912.

Singh K, Srivastava A, Prakash D, Das P K, Siddiqui A A and Raghivanshi S S. 2000. Ranking foliar constituents in morphotypes of muga food plant-Machilus bomycina King. Sericologia 40(2): 279-283.

Southwood, T. R. E., and P. A. Handerson. 2000. Ecological methods, with particular reference to the study of insect populations, 3rd edn. Blackwell Science, Oxford, UK.

Tikader, A., 2011. Cricula trifenestrata Helfer feed on different plants, -A new report. Geobios. 38:151-155.

Yadav, S. and A. Kumar. 2003. New record of wild silk caterpillar Cricula trifenestrata Helfer on large cardamon and notes on it's biology. Uttar Pradesh J. Zool. 23:67-69.

\section{How to cite this article:}

Gharde, S.K. and Chaudhuri, N. 2018. The Life History and Population Growth Parameters of Leaf Eating Caterpillar Cricula trifenestrata Helfer (Lepidoptera: Saturniidae) Infesting Manochilus bombycina King. Int.J.Curr.Microbiol.App.Sci. 7(02): 710-717. doi: https://doi.org/10.20546/ijcmas.2018.702.089 